\title{
In vivo triglyceride synthesis in subcutaneous adipose tissue of humans correlates with plasma HDL parameters
}

\author{
Demidmaa Tuvdendorj a, *, Alejandro O. Munoz a , Viviana Ruiz-Barros ${ }^{\text {b }}$, \\ Jean-Marc Schwarz ${ }^{\text {b }}$, Giuseppe Montalto ${ }^{c}$, Manisha Chandalia ${ }^{a}$, Lawrence C. Sowers ${ }^{\text {e }}$ \\ Manfredi Rizzo ${ }^{\mathrm{c}, \mathrm{d}}$, Elizabeth J. Murphy ${ }^{\mathrm{b}}$, Nicola Abate ${ }^{\mathrm{a}}$ \\ a Departments of Internal Medicine, University of Texas Medical Branch, Galveston, TX, USA \\ b University of California in San Francisco, San Francisco, CA, USA \\ c Biomedical Department of Internal Medicine and Medical Specialties, University of Palermo, Palermo, Italy \\ ${ }^{\mathrm{d}}$ Euro-Mediterranean Institute of Science and Technology, Palermo, Italy \\ e Pharmacology \& Toxicology, University of Texas Medical Branch, Galveston, TX, USA
}

\section{A R T I C L E I N F O}

\section{Article history:}

Received 7 March 2016

Received in revised form 7 June 2016

Accepted 10 June 2016

Available online 13 June 2016

\section{Keywords:}

Triglycerides

Adipocyte

HDL-C metabolism

Stable isotope tracer kinetics

Atheroprotective

Gender-related

Mass spectrometry

\begin{abstract}
A B S T R A C T
Backgrounds and aims: Low concentrations of plasma HDL-C are associated with the development of atherosclerotic cardiovascular diseases and type 2 diabetes. Here we aimed to explore the relationship between the in vivo fractional synthesis of triglycerides $\left(\boldsymbol{f}_{\mathbf{T G}}\right)$ in subcutaneous (s.q.) abdominal adipose tissue (AT), HDL-C concentrations and HDL particle size composition in non-diabetic humans.

Methods: The $\boldsymbol{f}_{\mathrm{TG}}$ in s.q. abdominal AT was measured in 16 non-diabetic volunteers ( 7 women, 9 men; Age: $49 \pm 20$ years; BMI: $31 \pm 5 \mathrm{~kg} / \mathrm{m}$; Fasting Plasma Glucose: $90 \pm 10 \mathrm{mg} / \mathrm{dl}$ ) after ${ }^{2} \mathrm{H}_{2} \mathrm{O}$ labeling. HDL-C concentration and subclasses, large (L-HDL), intermediate (I-HDL) and small (S-HDL) were measured. Results: Linear regression analyses demonstrated significant associations of $\boldsymbol{f}_{\text {TG }}$ with plasma concentration of HDL-C $(r=0.625, p=0.009)$ and percent contribution of L-HDL $(r=0.798, p<0.001)$, I-HDL $(r=-0.765, p<0.001)$ and S-HDL $(r=-0.629, p=0.009)$. When analyses were performed by gender, the associations remained significant in women (HDL-C: $r=0.822, p=0.023$; L-HDL: $r=0.892, p=0.007$; IHDL: $r=-0.927, p=0.003$ ) but not men.

Conclusions: Our study demonstrated an in vivo association between subcutaneous abdominal adipose tissue lipid dynamics and HDL parameters in humans, but this was true for women not men. Positive association with L-HDL and negative with I-HDL suggest that subcutaneous abdominal adipose tissue lipid dynamics may play an important role in production of mature functional HDL particles. Further studies evaluating the mechanism responsible for these associations and the observed gender differences are important and warranted to identify potential novel targets of intervention to increase the production of atheroprotective subclasses of HDL-Cs and thus decreasing the risks of development of atherosclerotic conditions.
\end{abstract}

๑) 2016 Elsevier Ireland Ltd. All rights reserved.

\section{Introduction}

A low concentration of plasma high density lipoprotein cholesterol (HDL-C) is associated with insulin resistance (IR),

Abbreviations: $f_{\mathrm{TG}}$, fractional synthesis of Triglycerides; L-HDL, large HDL; I-HDL, intermediate HDL; S-HDL, small HDL; $\mathrm{EM}_{1}$, excess mass isotopomer abundance for $\mathrm{M}_{1}$-glycerol; $\mathrm{A}^{\infty}{ }_{1}$, asymptotic mass isotopomer $\mathrm{M}_{1}$ abundance of a fully labeled glycerol.

* Corresponding author. Division of Endocrinology, Department of Internal Medicine, University of Texas Medical Branch, Galveston, TX, USA.

E-mail address: detuvden@utmb.edu (D. Tuvdendorj). atherosclerotic cardiovascular diseases (CVDs) and type 2 diabetes mellitus (T2DM) [1-6]. A 15-30\% lower concentration of HDL-C has been observed in patients with T2DM and impaired glucose tolerance (IGT) [7,8]. Despite this well-established association, recent therapeutic interventions to increase plasma concentration of HDLC have failed to demonstrate improved outcomes [9-11]. This may suggest that an increase in the amount of total HDL-C may not be enough to protect from CVDs; rather, an increase in functional HDL subclasses or change in HDL metabolism may be more important [12-16]. HDL particle assembly occurs in liver and intestine; however, rodent and in vitro studies have demonstrated that 
adipose tissue lipid dynamics appear to play an important role in the maturation of HDL particles and production of functional HDL particles $[14,15,17]$. No human studies have been done, however, looking for an in vivo association between adipose tissue lipid dynamics and HDL metabolism.

The dysfunction of adipose tissue, e.g., the reduced ability to accumulate excess calorie intake, has been proposed to play a significant role in the development of IR, T2DM and CVD $[18,19]$. Recently, we have shown that the inability of adipose tissue to synthesize triglycerides (TG) may result in increased spill-over of FFAs into circulation and contribute to the development of IR and the metabolic syndrome [20]. Thus, in the current study we evaluated the in vivo relationship between a parameter of subcutaneous (s.q.) abdominal adipose tissue lipid metabolism and plasma concentrations of HDL-C in non-diabetic adults. As a parameter of s.q. abdominal adipose tissue lipid metabolism we measured the fractional TG synthesis $\left(\boldsymbol{f}_{\mathrm{TG}}\right)$, which is an estimate of a fraction of adipose tissue TGs that have been newly synthesized over the period of labeling with deuterium water $\left({ }^{2} \mathrm{H}_{2} \mathrm{O} ; 21\right)$. Thus we evaluated the associations of $\boldsymbol{f}_{\text {TG }}$ with plasma concentration of HDL-C and also the percent distribution of HDL subclasses of different sizes, e.g., large (L-HDLs), intermediate (I-HDLs) and small (S-HDLs). The HDL particles comprise of a highly heterogeneous group of plasma lipoproteins, which differ by their density and the composition of specific proteins [22]. Although the functions of the different HDL subclasses remain largely unknown [23], the L-HDLs are generally known to be atheroprotective [24], while the I-HDLs and S-HDLs are considered to be lacking this property $[25,26]$. Finally, given the well-established gender differences in HDL-C $[27,28]$, we evaluated gender-related associations as well.

\section{Materials and methods}

\subsection{Subjects}

Men and women with stable diet and weight during the previous 6 months and stable medications for 90 days were eligible for the study. Exclusion criteria were any evidence of acute illnesses, diabetes mellitus (defined as fasting plasma glucose $(\mathrm{FPG})>126 \mathrm{mg} \mathrm{dl}^{-1}$ or taking medications that lower glucose), pregnancy or lactation, a history of substance abuse and the inability to provide informed consent. Two subjects ( 1 woman and 1 man) were taking metoprolol, otherwise no other subjects reported taking any medications known to affect glucose or lipid metabolism. All studies and procedures were approved by the Institutional Review Board at the University of Texas Medical Branch (UTMB), Galveston, TX, and all participants provided signed informed consent.

\subsection{Experimental protocol}

Upon enrollment, subjects received $50 \mathrm{ml}$ of $70 \%{ }^{2} \mathrm{H}_{2} \mathrm{O}$ (Cambridge Isotopes, Andover, MA, USA), three times a day for one week and $50 \mathrm{ml}$ twice daily, for the next 11 weeks (total of 12 weeks of ${ }^{2} \mathrm{H}_{2} \mathrm{O}$ labeling), as previously described $[20,21]$. This approach allows measuring the fraction of adipose tissue TGs that were newly synthesized during the labeling period. Quantitatively, it allows measurement of the degree of incorporation of ${ }^{2} \mathrm{H}$ into $\mathrm{C}-\mathrm{H}$ bonds of $\alpha$-glycerol phosphate, which is proportional to two factors: the fraction of labeled hydrogen atoms in tissue water (i.e., the enrichment of ${ }^{2} \mathrm{H}_{2} \mathrm{O}$ in whole body water) and the fraction of $\mathrm{C}-\mathrm{H}$ bonds in glycerol that are incorporated from body water. Thus, if the body water ${ }^{2} \mathrm{H}$ enrichment and the number of $\mathrm{C}-\mathrm{H}$ bonds in glycerol that derive from body water are known, the incorporation of ${ }^{2} \mathrm{H}$ into $\mathrm{H}$ atoms in the glycerol moiety of TGs reveals the fraction of newly synthesized TGs. Thus to measure the body water ${ }^{2} \mathrm{H}_{2} \mathrm{O}$ enrichment the saliva samples were collected weekly throughout the labeling period. To measure the incorporation of ${ }^{2} \mathrm{H}$ into $\mathrm{C}-\mathrm{H}$ bonds of $\alpha$-glycerol phosphate, adipose tissue biopsy samples were obtained at the end of the labeling period, as described previously [20]. Briefly, subcutaneous abdominal periumblical adipose tissue biopsy samples were obtained under sterile conditions and local anesthesia with $1 \%$ lidocaine. After a small incision, a biopsy needle (Bard Biopsy Systems, Crawley, UK) was used to obtain tissue samples. Additionally, blood samples were collected to measure clinical chemistry parameters and HDL-C values. The subjects also underwent Dual Energy X-ray Absorptiometry (DEXA, GE Lunar iDXA, GE Medical Systems Lunar, Madison, WI, USA) to measure body fat mass.

\subsection{Plasma lipid analyses}

Fasting blood samples obtained at the end of 12 weeks of ${ }^{2} \mathrm{H}_{2} \mathrm{O}$ labeling were used for the measurement of plasma VLDL-C, TG, TC, HDL-C and LDL-C; the analyses were done using a Vitros 5600 analyzer (Ortho Clinical Diagnostic, Rochester, NY, USA) in the Clinical Pathology Laboratory, UTMB.

The HDL subclass analyses were performed in the laboratory of M.R. and G.M. at the University of Palermo, Italy, in a blinded manner. Non-denaturing, linear polyacrylamide gel electrophoresis was used to separate the HDL subclasses and the measurements were done using the LipoPrint ${ }^{\mathrm{a}}$ System (Quantimetrix Corporation, Redondo Beach, CA, USA) as described below. This method has been validated against gradient gel electrophoresis and nuclear magnetic resonance (reviewed in [29]).

Twenty five $\mu \mathrm{l}$ of plasma sample was mixed with $300 \mu \mathrm{l}$ Lipoprint Loading Gel and placed upon the upper part of the 3\% polyacrylamide gel. After $30 \mathrm{~min}$ of photopolymerisation at room temperature, electrophoresis was performed for $50 \mathrm{~min}$ at $3 \mathrm{~mA}$. Each electrophoresis chamber involved two quality controls. The electrophoresed gels were then scanned, using the LipoPrint ${ }^{\mathrm{a}}$ System, to determine the relative area of each lipoprotein subfraction. After scanning, electrophoretic mobility and the area under the curve were calculated qualitatively and quantitatively. HDL subclasses were distributed as ten bands: HDL-1, HDL-2 and HDL-3 were defined as L-HDL; HDL-4, HDL-5, HDL-6 and HDL-7 were defined as I-HDL; HDL-8, HDL-9 and HDL-10 comprised the S-HDL fraction $[30,31]$. The relative area for each subclass or, in other words, its contribution into total lipoprotein fraction was expressed as a percentage (\%). This percent contribution of a subclass was multiplied by the total concentration of plasma HDL-C to yield the concentration of each subclass in $\mathrm{mg} \mathrm{dl}^{-1}$.

\subsection{Adipose tissue TG analyses}

Adipose tissue lipids were extracted with chloroform:methanol (2:1) Folch extraction; TG were isolated via thin layer chromatography. FA methyl esters were separated from glycerol. The fraction containing the glycerol was further derivatized to the glycerol triacetate derivative for GC/MS analysis [20,32]. TG-glycerol isotopic enrichments of the glycerol-triacetate derivative were determined by GC-MS (5971 and 5973 models, Hewlett-Packard, Palo Alto, CA, USA), using a DB-225 fused silica column, in methane chemical ionization mode monitoring mass-to-charge ratios $(m / z)$ of $159,160,161$ for $M_{0}, M_{1}$, and $M_{2}$ as previously described $[20,32]$.

\subsection{Measurement of ${ }^{2} \mathrm{H}_{2} \mathrm{O}$ enrichments in body water}

Enrichment of ${ }^{2} \mathrm{H}_{2} \mathrm{O}$ in body water was measured in saliva 
samples, as previously reported [20]. The integrated (AUC) exposure to heavy water for each subject was calculated as the area under the water enrichment time course for individual water enrichment measurements using the trapezoid method.

\subsection{Calculations for TG-glycerol synthesis from ${ }^{2} \mathrm{H}_{2} \mathrm{O}$}

TG newly synthesized during the ${ }^{2} \mathrm{H}_{2} \mathrm{O}$ administration was calculated as previously described using the following equation:

$\mathbf{f}_{\mathrm{TG}}(\%)=\mathrm{EM}_{1}[\mathrm{TG}$-glycerol $] / \mathrm{A}^{\infty}{ }_{1}[\mathrm{TG}$-glycerol $]$

where $\mathbf{f}$ is the fraction (\%) of newly synthesized TG molecules present, $\mathrm{EM}_{1}$ is the excess mass isotopomer abundance for $\mathrm{M}_{1}$ glycerol and $A^{\infty}{ }_{1}$ is the asymptotic mass isotopomer $M_{1}$ abundance of a fully labeled glycerol, and calculated, as described previously $[20,32]$.

\subsection{Statistical analyses and data presentations}

Data are presented as means $\pm \mathrm{SD}$. The differences in parameters between the groups of men and women were evaluated using 2tail, unequal distribution variance Student t-test. Relationship analyses were performed using a linear regression model. The $p<0.05$ was considered statistically significant.

\section{Results}

\subsection{Age, BMI and metabolic characteristics of study subjects}

Sixteen non-diabetic adults ( 9 men and 7 women) participated in the study; the characteristics of the subjects are presented in Table 1 for the entire group and for men and women separately. There was no change in body weight during the deuterium labeling period (data not shown). Men were significantly heavier $(p=0.038)$ and taller $(p=0.003)$ than the women; however there were no differences in either BMI $(p=0.247)$ or percent body fat mass $(p=0.060)$ though there was a trend toward greater fat mass in the women. One female subject had impaired fasting glucose concentration of $122 \mathrm{mg} \mathrm{dl}^{-1}$. Two women were menopausal (73 and 75 years old) with plasma HDL concentrations of 72 and $42 \mathrm{mg} \mathrm{dl}^{-1}$, respectively.

The plasma concentrations of glucose, lipids and HDL subclasses, as well as the \% contribution and concentrations of HDL subclasses, are also presented in Table 1.

There were no differences in fasting plasma glucose, TG, VLDL, LDL, total or HDL cholesterols. Interestingly, the percent contributions of S-HDL subclasses were significantly higher $(p=0.004)$ in men when compared to women, whereas L-HDL was lower $(p=0.004)$ and I-HDL was similar $(p=0.094$; Table 1$)$. The absolute concentration of L-HDL was also significantly higher in women than in men ( $p=0.013)$, however no differences in concentrations of I-HDL and S-HDL between the groups were observed (Table 1).

\subsection{Adipose TG kinetics}

The ${ }^{2} \mathrm{H}_{2} \mathrm{O}$ body water enrichment was stable over the course of the 12 week labeling protocol for individual subjects with an average enrichment of $1.6 \pm 0.4 \%$. The average fractional synthesis of TG $\left(\boldsymbol{f}_{\mathrm{TG}}\right)$ was $17 \pm 6 \%$ and there was a non-significant trend towards higher synthesis in women as compared to men $(20 \pm 6 \% v s$. $14 \pm 5 \%, p=0.057)$.

\subsection{Association between the HDL parameters and $\boldsymbol{f}_{T G}$}

First, we conducted association analyses for the whole group, including both men and women. Linear regression analyses showed that s.q. abdominal adipose tissue $\boldsymbol{f}_{\mathrm{TG}}$ significantly and positively correlated with the plasma concentration of total HDL $(r=0.627$, $p=0.009)$ and L-HDL $(r=0.936, p<0.001)$. However, no association was seen with the concentrations of I-HDL $(r=0.362$, $p=0.168)$ or S-HDL $(r=0.205, p=0.445)$. $\boldsymbol{f}_{\mathrm{TG}}$ also correlated positively with the \% contribution of the L-HDL subclass $(r=0.797$, $p<0.001$ ), but negatively with the \% contribution of the I-HDL $(r=-0.763, p<0.001)$ and S-HDL $(r=-0.628, p=0.009)$ subclasses.

We then conducted association analyses for men and women separately and the results are depicted in Fig. 1. In women, $\boldsymbol{f}_{\mathrm{TG}}$ significantly and positively correlated with the plasma concentration of total HDL (Fig. $1 \mathrm{~A} ; p=0.016$ ) and \% of L-HDL subclass

Table 1

Metabolic characteristics of study subjects.

\begin{tabular}{|c|c|c|c|c|}
\hline Parameters & All $(n=16)$ & Women $(\mathrm{n}=7)$ & $\operatorname{Men}(\mathrm{n}=9)$ & $p$ value \\
\hline Age (years) & $49 \pm 20$ & $48 \pm 18$ & $50 \pm 22$ & 0.898 \\
\hline \multicolumn{5}{|l|}{ Racial distribution } \\
\hline African American & 3 & 1 & 2 & - \\
\hline Caucasian & 13 & 6 & 7 & - \\
\hline Body weight (kg) & & $77 \pm 19$ & $98 \pm 17$ & 0.038 \\
\hline Height $(\mathrm{cm})$ & & $160 \pm 6$ & $172 \pm 7$ & 0.003 \\
\hline Body mass index $\left(\mathrm{kg} \mathrm{m}^{-2}\right)$ & $31 \pm 5$ & $30 \pm 6$ & $33 \pm 3$ & 0.247 \\
\hline$\%$ Body fat mass (\%) & $39 \pm 6$ & $42 \pm 7$ & $36 \pm 5$ & 0.060 \\
\hline Fasting glucose $\left(\mathrm{mg} \mathrm{dl}^{-1}\right)$ & $90 \pm 10$ & $92 \pm 14$ & $88 \pm 6$ & 0.440 \\
\hline Plasma triglyceride $\left(\mathrm{mg} \mathrm{dl}^{-1}\right)$ & $109 \pm 70$ & $81 \pm 40$ & $131 \pm 83$ & 0.171 \\
\hline Plasma VLDL triglyceride $\left(\mathrm{mg} \mathrm{dl}^{-1}\right)$ & $22 \pm 14$ & $16 \pm 8$ & $26 \pm 17$ & 0.168 \\
\hline Plasma total cholesterol $\left(\mathrm{mg} \mathrm{dl}^{-1}\right)$ & $180 \pm 34$ & $186 \pm 32$ & $176 \pm 36$ & 0.571 \\
\hline Plasma LDL cholesterol $\left(\mathrm{mg} \mathrm{dl}^{-1}\right)$ & $104 \pm 28$ & $109 \pm 25$ & $99 \pm 30$ & 0.509 \\
\hline Plasma HDL cholesterol ( $\left.\mathrm{mg} \mathrm{dl}^{-1}\right)$ & $55 \pm 14$ & $61 \pm 14$ & $50 \pm 14$ & 0.156 \\
\hline L-HDL subclass (\%) & $31 \pm 10$ & $38 \pm 9$ & $25 \pm 3$ & 0.004 \\
\hline I-HDL subclass (\%) & $48 \pm 4$ & $46 \pm 5$ & $50 \pm 3$ & 0.094 \\
\hline S-HDL subclass (\%) & $21 \pm 7$ & $16 \pm 6$ & $25 \pm 5$ & 0.004 \\
\hline L-HDL subclass ( $\mathrm{mg} \mathrm{dl}^{-1}$ ) & $18 \pm 9$ & $24 \pm 10$ & $13 \pm 5$ & 0.013 \\
\hline I-HDL subclass $\left(\mathrm{mg} \mathrm{dl}^{-1}\right)$ & $26 \pm 6$ & $27 \pm 4$ & $25 \pm 7$ & 0.448 \\
\hline S-HDL subclass ( $\mathrm{mg} \mathrm{dl}^{-1}$ ) & $11 \pm 4$ & $10 \pm 4$ & $12 \pm 3$ & 0.152 \\
\hline
\end{tabular}

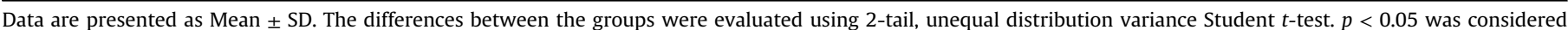
statistically significant.

VLDL, very low density lipoprotein; LDL, low density lipoprotein; HDL, high-density lipoprotein; L-HDL, large HDL; I-HDL, intermediate HDL; S-HDL, small HDL. 


\section{Women}
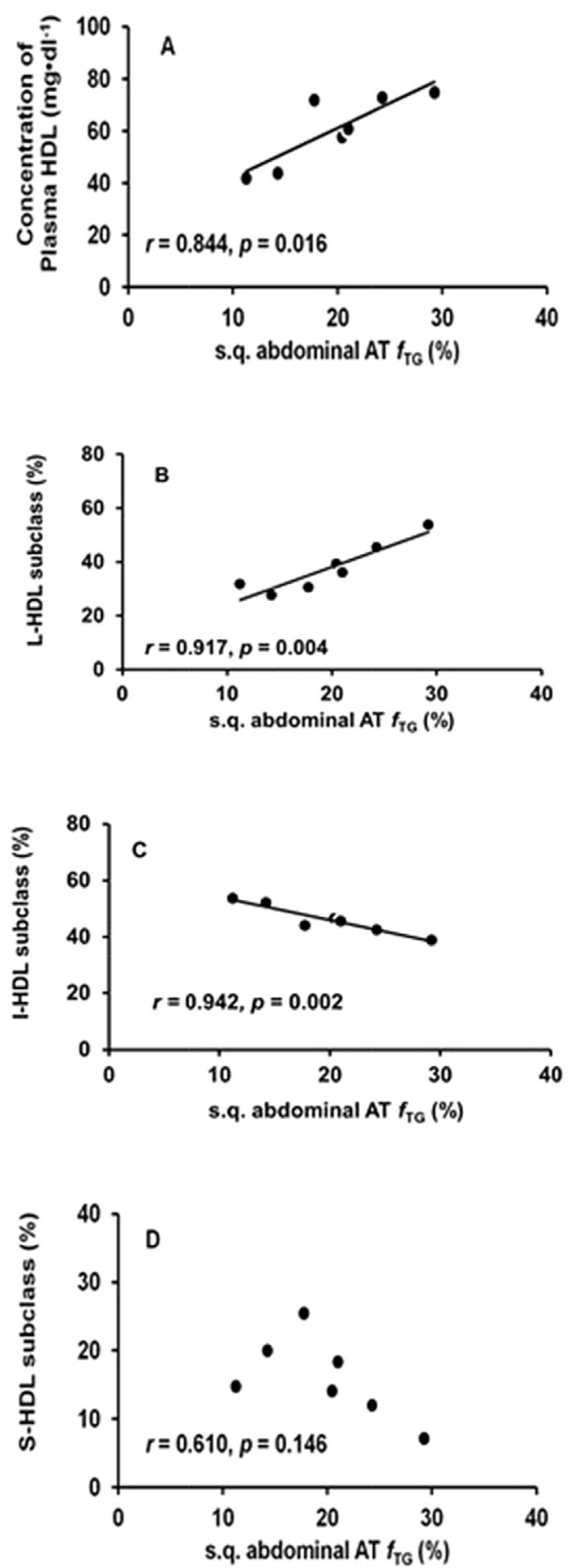

Men
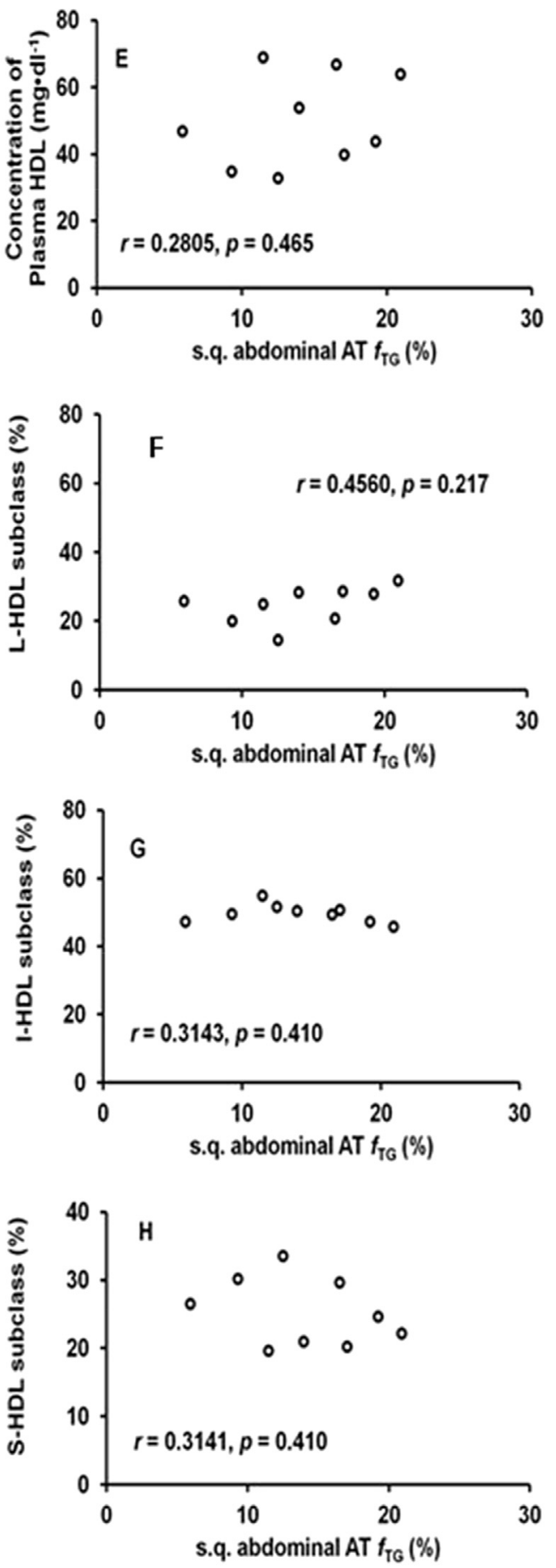

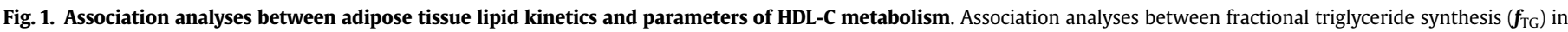

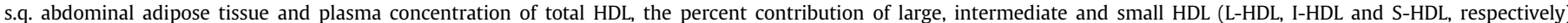

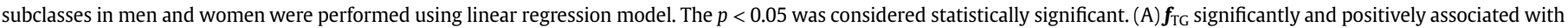

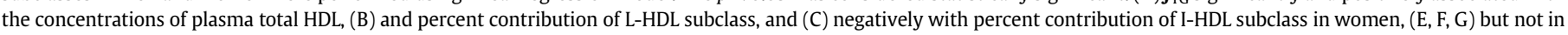
men. (D, H) No significant correlations were observed between $f_{\mathrm{TG}}$ and the percent contribution of S-HDL in either group.

(Fig. 1B; $p=0.004$ ), but negatively with \% of I-HDL subclass (Fig. 1C; $p=0.002$ ). No association was observed with \% of S-HDL subclass (Fig. 1D; $p=0.146$ ). Interestingly, no significant correlations between $\boldsymbol{f}_{\mathrm{TG}}$ and plasma concentration of HDL or \% contribution of HDL subclasses were observed in the men (Fig. 1E-H).

\section{Discussion}

Our results, for the first time, demonstrate an in vivo association between s.q. abdominal adipose tissue TG synthesis, a marker of adipose tissue lipid dynamics, and HDL-C metabolism in humans. 
We also report a gender difference in this association, which suggests a possible link between gender diversity in adipose tissue and HDL metabolism.

Given the atheroprotective effect of HDL, a large body of work has been produced regarding possible mechanisms responsible for decreased plasma HDL-C concentrations in conditions associated with high cardiovascular risk, such as obesity. Although incomplete, the current literature supports two important mechanisms involved in determining low HDL-C [33]. The first suggests that with increased plasma TG-rich particles there is increased exchange of TGs for cholesterol esters in HDL and LDL particles. Thus HDL particles become highly TG-enriched and are more easily degradable $[34,35]$. This mechanism suggests an indirect association between HDL metabolism and adipose tissue lipid dynamics. When adipose tissue is unable to efficiently store TGs there is increased FFA efflux from adipose tissue [18-20] and, subsequently, an increase in plasma TG-rich particles. The second proposed mechanism suggests that due to decreased efflux of cholesterol from adipose tissue, the lipidation process of HDL particles is inadequate and, thus, the HDL particles are unable to mature resulting in particles which are catabolized at higher rates [14,15,17,36-38]. ATP-binding cassette transporter A1 (ABCA1) and Scavenger receptor class B member 1 (SR-B1) have been shown to play a significant role in this process of HDL lipidation $[14,15,17]$. People with Tangier disease have mutation in $A B C A 1$ and have extremely low levels of HDL-C and apoA- 1 due to high rapid catabolism of the apolipoprotein as a result of its being poorly lapidated $[39,40]$. Genetic studies have shown that some rare alleles of ABCA1 associate with low levels of HDL-C and decreased efflux from monocyte-derived macrophages [41]. These data demonstrate the significance of HDL-C lipidation and the role of ABCA1 and SR-B1 in this process. Our results and the published data $[14,15,17,36-38]$ suggest a direct association between HDL metabolism and adipose tissue lipid dynamics. Though our study did not address the potential mechanisms involved, this is the first human in vivo support for an association between HDL metabolism and adipose tissue lipid dynamics in non-diabetic humans, independent of triglyceride elevation.

Our study also suggests a gender-specific association between the lipid dynamics in s.q. abdominal adipose tissue and HDL parameters (Fig. 1). Women have higher plasma HDL-C concentrations compared to men, and specifically have elevated levels of large apoA-I particles [26-28,42,43]. In our study, we did not observe differences in plasma concentration of total HDL-C between men and women, which may be explained by small sample size (Table 1). However, as previously shown [42], we did observe that the percent distribution of L-HDL particles is higher in women when compared to men, whereas that of S-HDL particles is higher in men (Table 1). We also observed that the percent distribution of L-HDLs positively correlated with s.q. abdominal adipose tissue TG synthesis in women (Fig. 1B), but not men (Fig 1F). If adipose tissue lipid dynamics are associated with HDL metabolism (e.g., production of functional HDL particles) this gender specific difference in these associations raises several questions: 1 ) how does hormonal status affect this interaction; and 2) how do different fat depots affect this interaction [43-45], e.g., abdominal vs. gluteal? Our current study does not answer these questions; however they deserve attention in future studies.

To evaluate the function of adipose tissue, we measured its ability to synthesize TGs. In our previous report on TG synthesis [20] we reported the $f_{\mathrm{TG}}$ data from ten subjects presented here and we demonstrated that $f_{\mathrm{TG}}$ associated positively with tissue insulin sensitivity, but negatively with plasma levels of FFAs. We hypothesized that the inability of adipose to accumulate excess calorie intake, or the inability of adipocytes to mature, may result in increased efflux of FFAs into circulation, which ultimately may result in ectopic fat deposition and the development of tissue insulin resistance [18-20]. Thus $f_{\mathrm{TG}}$ may represent a kinetic marker of adipose tissue lipid dynamics. Interestingly, in vitro studies demonstrated that stimulation of adipose tissue lipolysis results in increased efflux of both glycerol, a marker of lipolysis, and cholesterol $[17,43,44,46,47]$. Our study subjects maintained stable body weight during the deuterium labeling and in the steady state TG synthesis should equal the TG lipolysis. Thus subjects with higher $f_{\text {TG }}$ should have had higher TG lipolysis and higher cholesterol efflux from adipocytes. The impairment in adipocyte lipid dynamics may associate with both impaired TG turnover and cholesterol efflux/metabolism. If this hypothesis is true, it can partially explain low concentration of plasma HDL-C in metabolically compromised subjects, such as the obese and insulin resistant.

There are several limitations of this study. First, we have a relatively small sample size, which may explain the lack of difference in HDL concentrations between men and women. Second, we include pre and post-menopausal women. While it is well established post-menopausal women have on average a lower HDL-C [48], the two postmenopausal women (age: 73 and 75 years old) in our study had plasma HDL-C concentrations of 72 and $42 \mathrm{mg} \mathrm{dl}^{-1}$, respectively, which may suggest that, at least in this small study and especially in the group of women, there was no effect of age or hormonal status on the results and conclusions. Third, and perhaps most importantly, this is a cross-sectional study which does not reveal cause and effect relationships but rather is hypothesis generating for future mechanistic investigations.

In conclusion, our study for the first time demonstrated an in vivo association between s.q. abdominal adipose tissue lipid dynamics (e.g., $f_{\mathrm{TG}}$ ) and HDL parameters (e.g., plasma concentration of total HDL-C and relative contributions of HDL subtypes) in women but not men. Positive association with L-HDL and a negative association with I-HDL suggest that s.q. abdominal adipose tissue lipid dynamics may be important for the production of mature functional HDL particles and may provide new targets for developing therapeutic strategies to decrease cardiovascular risks. Further studies evaluating the mechanism responsible for these associations and the observed gender differences are important and warranted.

\section{Conflict of interest}

The authors declared that they do not have anything to disclose regarding conflict of interest with respect to this manuscript.

\section{Financial support}

This study was supported by the Institute for Translational Sciences at the UTMB, supported in part by a Clinical and Translational Science Award (\#UL1 TR001439) from the National Center for Advancing Translational Sciences, National Institutes of Health, and the Shriners Grant \#84090, Metabolism Unit, Shriners Hospitals for Children.

\section{Author contributions}

Conduction of clinical studies: DT, AOM, MC, NA.

Sample and data analyses: DT, AOM, VRB, JMS, GM, LCS, MR, EJM, NA.

Manuscript preparation: DT, NA

Manuscript editing: DT, AOM, JMS, GM, MC, LCS, MR, EJM, NA.

Obtaining funds: MC, EJM, NA. 


\section{Acknowledgements}

We would like to thank Drs. Dragana Nikolic and Rosaria Vincenza Giglio (Palermo, Italy) for the excellent technical assistance; Ms. Geetika Saraf and Ms. Doaa Abdelrahman for their excellent assistance with the recruitment of subjects and overall conduction of the study.

\section{References}

[1] M. Roden, T.B. Price, G. Perseghin, K.F. Petesen, D.L. Rothman, G.W. Cline, G.I. Shulman, Mechanism of free fatty acid-induced insulin resistance in humans, J. Clin. Investig. 97 (1996) 2859-2864.

[2] R.B. D’Agostino Sr., M.J. Pencina, J.M. Massaro, S. Coady, Cardiovascular disease risk assessment: insights from framingham, Glob. Heart 8 (1) (2013) 11-23.

[3] D.E. Kelley, K.V Williams, J.C Price, T.M. McKolanis, B.H Goodpaster, F.L. Thaete, Plasma fatty acids, adiposity, and variance of skeletal muscle insulin resistance in type 2 diabetes mellitus, J. Clin. Endocrinol. Metab. 86 (2001) 5412-5419.

[4] D.J. Gordon, B.M. Rifkind, High density lipoprotein: the clinical implications of recent studies, N. Engl. J. Med. 321 (1989) 1311-1316.

[5] P. Barter, A.M. Gotto, J.C. LaRosa, J. Maroni, M. Szarek, S.M. Grundy, J.J. Kastelein, V. Bittner, J.C. Fruchart, Treating to New Targets Investigators, HDL cholesterol, very low levels of LDL cholesterol, and cardiovascular events, N. Engl. J. Med. 357 (2007) 1301-1310.

[6] Emerging Risk Factors Collaboration, et al., Lipid-related markers and cardiovascular disease prediction, JAMA 307 (2012) 2499-2506.

[7] C.M. Burchfiel, R.F. Hamman, J.A. Marshall, J. Baxter, L.B. Kahn, J.J. Amirani, Cardiovascular risk factors and impaired glucose tolerance: the San Luis valley Diabetes Study, Am. J. Epidemiol. 131 (1990) 57-70.

[8] B.V. Howard, Lipoprotein metabolism in diabetes mellitus, J. Lipid Res. 28 (1987) 613-628.

[9] M.E. Brousseau, E.J. Schaefer, M.L. Wolfe, L.T. Bloedon, A.G. Digenio, R.W. Clark, J.P. Mancuso, D.J. Rader, Effects of an inhibitor of cholesteryl ester transfer protein on HDL cholesterol, N. Engl. J. Med. 350 (2004) 1505-1515.

[10] J.M. McKenney, M.H. Davidson, C.L. Shear, J.H. Revkin, Efficacy and safety of torcetrapib, a novel cholesteryl ester transfer protein inhibitor, in individuals with below-average high-density lipoprotein cholesterol levels on a background of atorvastatin, J. Am. Coll. Cardiol. 48 (2006) 1782-1790.

[11] T.F. Lüscher, S. Taddei, J.C. Kaski, J.W. Jukema, D. Kallend, T. Münzel, J.J. Kastelein, J.E. Deanfiedl, dal-VESSEL Investigators, Vascular effects and safety of dalcetrapib in patients with or at risk of coronary heart disease: the dal-VESSELrandomized clinical trial, Eur. Heart J. 33 (2012) 857-865.

[12] H.B. Brewer, HDL metabolism and the role of HDL in the treatment of highrisk patients with cardiovascular disease, Curr. Cardiol. Rep. 9 (2007) 486-492.

[13] R.S. Rosenson, Functional assessment of HDL: moving beyond static measures for risk assessment, Cardiovasc Drug Ther. 24 (2010) 71-75.

[14] S. Chung, J.K. Sawyer, A.K. Gebre, N. Maeda, J.S. Parks, Adipose tissue ATP binding cassette transporter A1 contributes to high-density lipoprotein biogenesis in vivo, Circulation 124 (2011) 1663-1672.

[15] Y.Z. Zhang, F.C. McGillicuddy, C.C. Hinkie, S. O’Neill, J.M. Glick, G.H. Rothblat, M.P. Reilly, Adipocyte modulation of high-density lipoprotein cholesterol, Circulation 121 (11) (2010) 1347-1355.

[16] D.J. Rader, A. Daugherty, Translating molecular discoveries into new therapies for atherosclerosis, Nature 451 (7181) (2008) 904-913.

[17] P.B. Verghese, E.L. Arrese, J.L. Soulages, Stimulation of lipolysis enhances the rate of cholesterol efflux to HDL in adipocytes, Mol. Cell Biochem. 302 (2007) $241-248$.

[18] E. Ravussin, S.R. Smith, Increased fat intake, impaired fat oxidation, and failure of fat cell proliferation result in ectopic fat storage, insulin resistance, and type 2 diabetes mellitus, Ann. N. Y. Academ Sci. 967 (2002) 363-378.

[19] S. Virtue, A. Vidal-Puig, Adipose tissue expandability, lipotoxicity and the metabolic syndrome - an allostatic perspective, Biochim. Biophys. Acta 1801 (2010) 338-349.

[20] D. Tuvdendorj, M. Chandalia, T. Batbayar, M. Saraf, C. Beysen, E.J. Murphy, N. Abate, Altered subcutaneous abdominal adipose tissue lipid synthesis in obese, insulin resistant humans, Am. J. Physiol. Endocrinol. Metab. 305 (8) (2013) E999-E1006.

[21] S.M. Turner, E.J. Murphy, R.A. Neese, F. Antelo, T. Thomas, A. Agarwal, C. Go, M.K. Hellerstein, Measurement of TG synthesis and turnover in vivo by $2 \mathrm{H} 2 \mathrm{O}$ incorporation into the glycerol moiety and application of MIDA, Am. J. Physiol. Endocrinol. Metab. 285 (2003) E790-E803.

[22] S. Oravec, E. Dostal, A. Dukát, P. Gavorník, M. Kucera, K. Gruber, HDL subfractions analysis: a new laboratory diagnostic assay for patients with cardiovascular diseases and dyslipoproteinemia, Neuro Endocrinol. Lett. 32 (2011) 502-509.

[23] M. Rizzo, J.D. Otvos, D. Nikolic, G. Montalto, P.P. Toth, M. Banach, Subfractions and subpopulations of HDL: an update, Curr. Med. Chem. 21 (25) (2014) 2881-2891.

[24] B.F. Asztalos, L.A. Cupples, S. Demissie, K.V. Horvath, C.E. Cox, M.C. Batista, E.J. Schaefer, High density lipoprotein subpopulation profile and coronary heart disease prevalence in male participants of the Framingham Offspring Study, Arterioscler. Thromb. Vasc. Biol. 24 (2004) 2181-2187.

[25] J.D. Otvos, D. Collins, D.S. Freedman, I. Shalaurova, E.J. Schaefer, J.R. McNamara, H.E. Bloomfield, S.J. Robins, Low-density lipoprotein and highdensity lipoprotein particle subclasses predict coronary events and are favorably changed by gemfibrozil therapy in the Veterans Affairs HighDensity Lipoprotein Intervention Trial, Circulation 113 (2006) 1556-1563.

[26] P. Blackburn, I. Lemieux, B. Lamarche, J. Bergeron, P. Perron, G. Tremblay, D. Gaudet, J.P. Despres, Angiographically-assessed coronary artery disease associates with HDL particle size in women, Atherosclerosis 223 (2012) 359-364.

[27] C.M. Williams, Cardiovascular risk factors in women, Proc. Nutr. Soc. 56 (1997) 383-391.

[28] W.R. Hazzard, D. Applebaum-Bowden, Why women live longer than men: the biologic mechanism of the sex differential in longevity, Transac. Am. Clin. Climatol. Assoc. 101 (1990) 168-188.

[29] D.P. Mikhailidis, M. Elisaf, M. Rizzo, K. Berneis, B. Griffin, A. Zambon, V. Athyros, J. de Graff, W. Marz, K.G. Parhofer, G.B. Rini, G.A. Spinas, G.H. Tomkin, A.D. Tselepis, A.S. Wierzbicki, K. Winkler, M. Florentin, E. Liberopoulos, European panel on low density lipoprotein (LDL) subclasses: statement on the pathophysiology, atherogenicity and clinical significance of LDL subclasses, Curr. Vasc. Pharmacol. 9 (2011) 533-571.

[30] W. Fendler, M. Rizzo, M. Borowiec, B. Malachowska, K. Antosik, A. Szadkowska, M. Banach, M. Urbanska-Kosinska, M. Szopa, M.T. Malecki, W. Mlynarski, Less but better - cardioprotective lipid profile of patients with GCK-MODY despite lower HDL-cholesterol level, Acta Diabetol. 51 (4) (2014) 625-632.

[31] D.M. Hoefner, S.D. Hodel, J.F. O’Brien, E.L. Branum, D. Sun, I. Meissner, J.P. McConnell, Development of a rapid, quantitative method for LDL subfractionation with use of the Quantimetrix Lipoprint LDL System, Clin. Chem. 47 (2) (2001) 266-274.

[32] R.R. Wolfe, D.L. Chinkes, Isotope Tracers in Metabolic Research: Principles and Practice of Kinetic Analysis, second ed., Wiley-Liss, New York, New York, USA 2005.

[33] F.C. McGillicuddy, M.P. Reilly, Adipose tissue modulation of HDL, Clin. Lipidol. 5 (5) (2010) 601-606.

[34] B. Lamarche, K.D. Uffelman, A. Carpentier, J.S. Cohn, G. Steiner, P.H. Barrett, G.T. Lewis, Triglyceride enrichment of HDL enhances in vivo metabolic clearance of HDL apo A-I in healthy men, J. Clin. Investig. 103 (8) (1999) 1191-1199.

[35] S. Rashid, P.H. Barrett, K.D. Uffelman, T. Watanabe, K. Adeli, G.F. Lewis, Lipolytically modified triglyceride-enriched HDLs are rapidly cleared from the circulation, Arterioscler. Thromb. Vasc. Biol. 22 (3) (2002) 483-487.

[36] j Ji, G.F. Watts, A.G. Johnson, D.C. Chan, E.M.M. Ooi, K. Rye, A.P. Serone, H.R. Barrett, High-density lipoprotein (HDL) transport in the metabolic syndrome: application of a new model for HDL particle kinetics, J. Clin. Endocrinol. Metab. 91 (2006) 973-979.

[37] J. Pietzsch, U. Julius, S. Nitzsche, M. Hanefeld, In vivo evidence for increased apoliporotein A-1 catabolism in subjects with impaired glucose tolerance, Diabetes 47 (1998) 1928-1934.

[38] A. Mulya, J.Y. Lee, A.K. Gebre, M.J. Thomas, P.L. Colvin, J.S. Parks, Minimal lipidation of pre- HDL by ABCA1 results in reduced ability to interact with ABCA1, Arterioscler. Thromb. Vasc. Biol. 27 (2007) 1828-1836.

[39] H.H. Hobbs, D.J. Rader, ABC1: connecting yellow tonsils, neuropathy, and very low HDL, J. Clin. Investig. 104 (1999) 1015-1017.

[40] A. von Eckardstein, Differential diagnosis of familial high density lipoprotein deficiency syndromes, Atherosclerosis 186 (2006) 231-239.

[41] A. Soro-Paavonen, J. Naukkarinen, M. Lee-Rueckert, H. Watanabe, E. Rantala, S. Soderlund, A. Hiukka, P.T. Kovanen, M. Jauhiainen, L. Peltonen, M.R. Taskinen, Common ABCA1 variants, HDL levels, and cellular cholesterol efflux in subjects with familial low HDL, J. Lipid Res. 48 (2007) 1409-1416.

[42] N. Duverger, D. Rader, H.B. Brewer, Distribution of subclasses of HDL containing ApoA-I without ApoA-II (LpA-I) in normolipidemic men and women, Arterioscler. Thromb. 14 (1994) 1594-1599.

[43] F. Magkos, B.S. Mohammed, B. Mittendorfer, Effect of obesity on the plasma lipoprotein subclass profile in normoglycemic and normolipidemic men and women, Int. J. Obes. 32 (11) (2008) 1655-1664.

[44] T. Tchkonia, T. Thomou, Y. Zhu, I. Karagiannides, C. Pothoulakis, M.D. Jensen, J.K. Kirkland, Mechanisms and metabolic implications of regional differences among fat depots, Cell Metab. 17 (5) (2013) 644-656.

[45] L.A. Anderson, P.G. McTernan, A.H. Barnett, S. Kumar, The effects of androgens and estrogens on preadipocyte proliferation in human adipose tissue: influence of gender and site, J. Clin. Endocrinol. Metab. 86 (10) (2001) 5045-5051.

[46] S. Le Lay, C. Robichon, X. Le Liepvre, G. Dagher, P. Ferre, I. Dugail, Regulation of ABCA1 expression and cholesterol during adipose differentiation of 3T3-L1 cells, J. Lipid Res. 44 (2003) 1499-1507.

[47] S. Le Lay, S. Krief, C. Farnier, I. Lefrère, X. Le Liepvre, R. Bazin, P. Ferre, I. Dugail Cholesterol, a cell size-dependent signal that regulates glucose metabolism and gene expression in adipocytes, J. Biol. Chem. 276 (20) (2001) 16904-16910.

[48] C. Nerbrand, J. Lidfeldt, P. Nyberg, B. Schersten, G. Samsioe, Serum lipids and lipoproteins in relation to endogenous and exogenous female sex steroids and age. The Women's Health in the Lund Area (WHILA) study, Maturitas 48 (2004) 161-169. 